\title{
Study on Internet Marketing Practices of Tourism Industry by Travel Agency of Nepal
}

\author{
Omprakash Pd. Yadav \\ Lecturer, Nepal Commerce Campus
}

\begin{abstract}
Nepal is famous destination for international travelers through tour started only after sixties. Nepal within two decades became successful to have it significant position in world tourism scenario. Tourism in Nepal becomes a strong contributor in National economy after it boomed in eighties. It has become important foreign export being major source of foreign exchange. A part from this, it has been contributing in creating direct \& indirect employment opportunities. Realizing the importance of tourism sector to uplift national economy, Nepal government has formulated various policies plan, and strategies to develop tourism as sustainable industry. Tourism master plan 1972 was an important step in policy formulation Nepal Tourism Board (NTB) was established in 1999 with the principle of Public Private Partnership (PPP) with the Principle of Public Private Partnership (PPP) approach. Since then, NTB has been marketing "Nepal as an enchanting holiday destination in world tourism market. It has adopted various strategies and undertaken different activities in order to promote Nepal as a must visit destination. We have abundant resources for which the country enjoys competitive advantages. Tourism represent one among such sectors which could rebuild the image of the country bringing back multifaceted benefit to the country and the people at large it also emerged as an exemplary model for the Nepalese economy and represent around 4\% to the country GDP and is also a major source of employment, it has developed as an independent sector of the economy heavily involving the Nepalese private sector. Travel agencies are among such private sector wings which are responsible to bring or has contributed to great extent to invite lots of tourist from all over the world. So to great extent promotion of tourism by these travel agencies has direct correlation with the inflow of tourist in Nepal.
\end{abstract}

In order to find the perception of travel agencies regarding internet marketing prospect practiced in tourism sector.

\section{Introduction}

Tourism denotes the temporary, short-term movement of people to destination outside the place where they normally live and work and their activities during the stay at these destinations. Much of this movement is international in character. Tourism is major element in the balance of payment of many countries which has grown faster than the trade in goods. Tourism generates employments \& income. It makes use of resources which may not be used otherwise in particular of unemployed labour in developing countries with few alternative source of employment. It can directly influence living standard and quality of life which lead to the satisfaction of the visitors and multiple benefit to the destination visited i.e. employment generation, economic 


\section{Pravaha Journal-2018}

growth, conservation of natural and cultural heritage, culture exchange etc. Tourism has always helped the local economy by improving standard, education, health care, social awareness and infrastructure development and so on.

In modern day concept, many scholars have defined tourist and tourism in different ways namely technically, experimentally, psychologically, anthropologically, sociologically and commercially. The most widely accepted but technical definition is the one proposed by the International Union of Official Travel Organization (IUOTO) in 1963, which was approved by the world tourist organization. It states that "Tourists are temporary visitors staying at least 24 hours in the country visited and the purpose of whose journey can be classified either as leisure, pleasure or business.

Nepal has been known as diversely rich in culture and environment and has been called a heaven for adventure travelers around the world. There have been various problems and obstacles preventing a successful development of tourism in the remote mountain country but till today Nepal in itself is proud of its with culture country economy, local people and environmental landscape. Since the beginning of the country's economical welfare tourism has been is the largest industry in Nepal and the largest source of foreign exchange and revenue. The main resources of Nepal as a leading tourism country are the eight of the tenth highest mountains in the world. Nepal is a hotspot destination for mountaineers rock climbers and people seeking adventures. The heritage of the Hindu and Buddhist religion in Nepal and incredible cold weather are also strong attractions. The speed of change in the global tourism and hospitality industries means that tourism businessholder need to be kept updated with contemporary trends of marketing phenomena.

Nepal is land of unparallel variety and situated between the two emerging superpower country China and India. Its total area is 1,47,181 sq. kilometers. Nepal is divided length wise into three strips. They are Himalayan, Terai belt and hills. Nepal has a variety of birds, animals, reptiles, flowers, vegetation and others. In Nepal 59 ethnic group and major ethnic groups are Newars, Rai, Chepang, Limbu, Magar, Gurung, Tharu, Sherpa, and Raute. Majority of them are Hindu and some are Buddhist. That means Nepal is multicultural multi linguistic, multi religious country. In spite of the presence of different religious and caste, there is religious harmony and tolerances among the peoples.

Unlimited potential for tourism development exists in Nepal on account of her natural beauty, geographical diversity and rich artistic heritage, daily life of Nepalese peoples. The desire and attitudes of human being vary in nature. So people travel from one place to another place for the purpose of adventure expedition recreation, study, business and mission. The activity connected with providing accommodation services and entertainment for people who are visiting a place for pleasure is called tourism.

Tourism has got a great prospect in Nepal due to the natural beauty cultural diversity and geographical structure, tourism has proved to be very important in Nepal. Tourism industry has also played a significant role in the unliftment of Nepalese economy. It contributes the $10.4 \%$ of total foreign exchange and $2.9 \%$ of gross domestic economy. It also has direct effect on social-cultural and economic life of Nepalese people. However tourism was promulgated in Nepal only 5 decades ago. The history of tourism industry in Nepal can be traced back to the mid 20th century.

Nepal was closed to foreign tourist till 1951/1952. The door of tourism was only 
opened in Nepal with the ascent of Mr. Everest in 1953 then Nepal became open to foreign tourist. The western aggravated by the impact of Second World War, attracted by easily available marijuana. It was free at that time flocked to Nepal.

The tourism industry achieved next landmark for its promotion and upliftment after establishment of Department of Tourism in 1959 by the Government efforts. The tourism act is promulgated in 1964. The effort for tourism development in Nepal continued with the design of master plan tourism in 1972.

The "Visit Nepal Year 1998" campaign has been the landmark in the history of tourism in Nepal. The Visit Nepal Year (VNY) was declared throughout Nepal with different programmes in January 1998. The Nepalese tourism jumped another hurdle after the establishment of Nepal Tourism Board (NTB). Department of tourism was converted to NTB on the 1st January 1999.

The government is placing high priority to tourism sector in its new economic development policy as there is a favourable situation in the country's political scenario and the government is all prepared for economic revolution in next 10 years for the upliftment of the massages. In this regard, the government of Nepal has launched a National tourism campaign "Nepal tourism year 2011" with a set target of at least one million international tourism by the year 2011 with the badge of adventure destination glittering and the adage "Atithi Devo Bhava" (Guests are gods) that reflects "Atithi ko satkar, Nepali ko sanskar" (Hospitality is Nepalese culture).

Marketing its tourism play most critical part. Tourism marketing is defined as "Systematic and co-ordinate effort exerted by the National Tourism Organizations (NTOs) and the tourist enterprises at international, National and local level to optimize the satisfaction of tourists, groups and individuals, in view of the sustained tourism growth" as per Burkart and Medlick. So tourism marketing is the joint effort of the components involved in it. No tourism planning or programmes will be successful without joint effect. A new and extremely powerful tool that can be used to remain competitive and successful investment the world of tourism marketing is the internet. The Internet's potential is so great that some have described it as a "Marketing Bonanza". The internet is a means of communication that allows data transfer between computers. It is originally designed as a military communication tool.

Internet users worldwide, search the internate for information. Potential tourists can use the net to research destination this is appealing for both independent travelers and those wishing to travel with a group inclusive tour. Operators based in destination as well as home countries can advertise their products on the Internet and take booking directly from customers. Hotel and airlines can use sophisticated databases to allow customer to make booking directly online and take payment by credit card.

The World Wide Web (www) is the fastest growing market place. And power of Internet cannot be ignored. Internet marketing can reduce marketing costs dramatically. The free marketing tool invented ever email. Due to the awareness of Internet marketing i.e. e-marketing, existence of website does not mean you will get customer all depends on the effective promotion. The starting point in formulating an effective Internet marketing strategy is to identify the need of customer who will visit the website. Given this background, this paper attempts to shed some light on the e-marketing prospects practiced in tourism industry by travel agencies in Nepal and how travel agencies can helps future tourism development in the country through 
effective hi-tech method of marketing.

\section{Statement of the Problem}

In Nepal economy tourism sector is playing a crucial role. It is the major source of foreign exchange earnings. Natural beauties, unique culture and traditional, rivers, mountains, caves etc. are the major attraction of tourist. The potentialities on tourism are very high in Nepal due to these attractions. At the present Nepalese tourism industry surrounded by numerous problem such as lack of effective plan policy and strategy, effective marketing, infrastructure, superstructure, security and so on.

Some of question regarding the problem are:

- What is the popularity of Internet as marketing tools among travel agencies?

- How is internet based tourism marketing and its significance in the tourism industry?

\section{Objectives of the study}

The general objectives of the present study aim to explore the role and value on tourism industry through Internet marketing in Nepal. The specific objectives of the study were follows:

- To examine popularity of internet as marketing tools among travel agencies.

- To analyze the internet base tourism marketing and its significance in the tourism industry.

\section{Limitation of the study}

Every study does have its own limitation and this study is no exception. The limitations of the study are as follows.

- Very limited relevant primary data are available due to the limited previous research undertaken.

- Travel agencies may not want to share the Internet marketing promotional strategies with outsiders. So they hesitate to respond easily during questionnaire survey.

- Tourism industry includes many industries like airlines, hotels, transport etc. So this study does not represent the data from whole tourism industry.

- It is not possible to collect data from entire tourism industry, so it may not be proper output to find out the perception of internet marketing among travel agency.

- Study area is small and oriented to Kathmandu Valley only.

\section{Literature Review}

"National Tourism Promotion Report 1983" was prepared by Nepal Tourism Promotion Committee of 1981, suggestions were also provided on marketing strategies and plan for tourism. It reemphasized the need for promoting Nepal style tourism as mentioned in the Nepal tourism master plan which would include sightseeing, trekking and wildlife adventure and which would promote Nepal as a primary destination. The major suggestion given from this report are to develop resorts in the mid mountains 
to encourage tourists from India during the hot Indian summer season, promotion in Europe be stepped up, special programs be designated for Buddhist pilgrims from Asian countries and that similar pilgrimage package be designated for Hindu pilgrims from India, depute a person in the embassies of Nepal for promoting tourism, participate investment various important trade fairs and to promote convention tourism.

"Nepal Tourism Master Plan Review" (1984) is a review study and it has suggested action program for implementation for the promotion of tourism in Nepal. This study contains three parts. In part one, a background to be 1972 Tourism Master, its contents and intents, and its practical use and operation together with a comprehensive review of past developments in key area of tourism. Part two sets forth an updated set of policy, objectives and market development concept forth five years and part three provides action oriented recommendation. According to this review report, there is no need for a new comprehensive master plan in tourism. The 1972 Master plan is relevant in its long term policy contents and most of its basic conceptual assumptions have been fully verified.

Pokharel (2003), has also prepared a separate review article entitled "Summary of past marketing strategies and plans for tourism in Nepal" with description of the study and seminar report related to Nepalese tourism marketing encompassing important studies and seminar proceeding with an emphasis on marketing of Nepalese Tourism.

NTB (2013), the present policy expects to introduce Nepal as an attractive, beautiful and self destination in the international tourism map with increased employment opportunity for livelihood, productivity and living standard of general public and economic growth along with contribution in the revenue due to the increase in various activities and enterprises of tourism sector such as airlines, Hotel, travel and tour by providing opportunity of livelihood and productivity to common people, by increasing the diverse tourism activity and enterprise like airlines,, Hotel, Travel and tour along with improvement of people living standard and economic development and contribution to revenue. This will develop ownership of local community especially in the area or rural tourism and competitiveness in quality services.

\section{Research Methodology}

The descriptive research design has been adopted to undertake fact finding operation searching for adequate information in the context of efficiency in tourism sectors. For the purpose, primary data collection, field survey was conducted. During the survey in addition to reading materials, the means of gathering the data and information included both questionnaire and interview technique have been used in order to collect the data for the study. For the data collection questionnaire, data will be collected from authorized personnel of travel agency. Apart from the questionnaires, some unstructured interviews will be also taken to collect more information about tourism sector and their difficulties. The collected data from questionnaire will be transformed and tabulated. Information will be grouped, sub grouped and classified as necessary.

\section{Data Analysis and Presentation}

There were several steps to analyze finding of the research. The steps referred to 
research questions and helped to find out the Internet marketing prospects practiced in tourism industry by travel agencies in Nepal. Major objective of the study is to find out the current trends of internet marketing practice by travel agencies in Nepal. In the respond on the objective of this research, view of travel agents is analyzed.

Analysis of the respondent's opinion on most suitable promotion medium:

Table No.1 Distribution of the respondent's view about choice of promotion medium

\begin{tabular}{|c|c|c|}
\hline \multirow{2}{*}{ Promotional Medium } & \multicolumn{2}{|c|}{ Respondents } \\
\hline & Number & $\%$ response \\
\hline E-Marketing & 5 & $10 \%$ \\
\hline Website & 8 & $16 \%$ \\
\hline Magazines & 0 & $0 \%$ \\
\hline Personal contract & 37 & $74 \%$ \\
\hline Total & 50 & $100 \%$ \\
\hline
\end{tabular}

Source: Field survey

From above table no. 1 shows that most people prefer personal contract as promotional medium rather than promoting through other promotional medium.

Analysis of the Respondent's view about do you have website:

No.2 Table Distribution of the respondent's whether they have website or not

\begin{tabular}{lccc}
\hline \multirow{2}{*}{ Status } & \multicolumn{2}{c}{ Respondents } \\
\cline { 2 - 3 } & Number & $\%$ response \\
\hline Yes & 48 & $96 \%$ \\
No & 2 & $4 \%$ \\
\hline Total & 50 & $100 \%$ \\
\hline
\end{tabular}

Source: Field survey

Above table no.2 shows that majority of travel agencies do have website only few travel agencies do not have website.

Analysis of the respondent's using internet in term of time frame

Table No.3 Distribution of the respondent's using Internet in term of time duration

\begin{tabular}{lcc}
\hline \multirow{2}{*}{ Time Duration } & \multicolumn{2}{c}{ Respondents } \\
\cline { 2 - 3 } & Number & $\%$ response \\
\hline Less than 1 year & 0 & $0 \%$ \\
1 to 5 years & 34 & $68 \%$ \\
6 to 10 years & 12 & $24 \%$ \\
More than 10 years & 4 & $8 \%$ \\
\hline Total & 50 & $100 \%$ \\
\hline
\end{tabular}

Source: Field survey

Above table no. 3 shows that majority of responds had been using Internet form 1 to 5 years.

Analysis of the respondent's idea about e-marketing 
Pravaha Journal-2018

Table No.4 Distribution of the respondent's idea on e-marking

\begin{tabular}{lccc}
\hline \multirow{2}{*}{ Idea on e-marketing } & \multicolumn{2}{c}{ Respondents } \\
\cline { 2 - 3 } & Number & $\%$ response \\
\hline Yes & 37 & $74 \%$ \\
No & 13 & $26 \%$ \\
\hline Total & 50 & $100 \%$ \\
\hline
\end{tabular}

Source: Field survey

Above table no. 4 shows that most of the travel agent have ideas about e-marketing. This is impressive \& encouraging result for tourism sector.

Analysis of the respondent's method of e-mail marketing

Table No.5 Distribution of the respondent's method of e-mail marketing

\begin{tabular}{lcc}
\hline \multirow{2}{*}{ Method } & \multicolumn{2}{c}{ Respondents } \\
\cline { 2 - 3 } & Number & $\%$ response \\
\hline Normal e-mail & 37 & $92.5 \%$ \\
New content notification & 3 & $7.5 \%$ \\
News letters & 0 & $0 \%$ \\
Bull E-mail marketing & 0 & $0 \%$ \\
\hline Total & 40 & $100 \%$ \\
\hline
\end{tabular}

Source: Field survey

Above table no.5 shows that majority of respondent are using normal email to inform or promote its services to the outside.

Analysis of the respondent's reason for not implementing internet as promotional tools

Table No.6 Distribution of the respondent's reason for not implementing internet

\begin{tabular}{lcc}
\hline & \multirow{2}{*}{ Reason } & \multicolumn{2}{c}{ Respondents } \\
\cline { 2 - 4 } & Number & $\%$ response \\
\hline Lack of fund & 5 & $26.32 \%$ \\
Lack of knowledge & 14 & $73.68 \%$ \\
Inefficient medium & 0 & $0 \%$ \\
Others & 0 & $0 \%$ \\
\hline Total & 19 & $100 \%$ \\
\hline
\end{tabular}

\section{Source: Field survey}

Above table no. 6 shows that most of the travel agencies are not implementary internet as promotional tools due to lack of knowledge.

Analysis of the respondent's of contribution made by internet for the promotion of tourism in Nepal.

Table No.7 Distribution of the respondent's rating about internet contribution

\begin{tabular}{lccc}
\hline \multirow{2}{*}{ Status } & \multicolumn{2}{c}{ Respondents } \\
\cline { 2 - 3 } & & Number & $\%$ response \\
\hline Poor & 2 & $4 \%$ \\
\hline
\end{tabular}




\begin{tabular}{lcc}
\hline \hline \multirow{2}{*}{ Status } & \multicolumn{2}{c}{ Respondents } \\
\cline { 2 - 3 } & Number & $\%$ response \\
\hline Satisfactory & 43 & $86 \%$ \\
Good & 5 & $10 \%$ \\
Very good & 0 & $0 \%$ \\
Total & 50 & $100 \%$ \\
\hline
\end{tabular}

Source: Field survey

Above table no.7 shows that majority of respondents were satisfy by the contribution made by internet for promoting tourism in Nepal.

\section{Conclusion}

- The most crucial factor is that without correct promotion and marketing of Nepal as tourism destination and marketing product for potential tourists flow will not increase. Though travel agencies are playing vital role for promoting Nepal as tourist destinations in its own way and knowledge of internet seems satisfactory but the way of marketing through internet seems minimal.

- Travel agencies must not overlook the fact that a new trend in international tourist is emerging. Before every visit to any country, tourist are more concern about the security and activities that region can offer. The get all those information through websites, travel agencies have abundance to packages to offer the only concern at present is lack of security to tourist and proper way of doing marketing on internet. If the current problem solved and travel agencies undertake internet as promotional tools definitely the flow of tourist will rise.

- Almost all the respondents were satisfied by the contribute on made by internet but due to lack of knowledge and fund they were not implementing as promotional tools in effective manner. Though they are using email in regular basis for getting in touch with the clients and have common responses regarding its advantages like effectiveness, exposure to outside world, time saving and cost saving. The entire respondents consensus that present tourism is badly hit by internal problem such as natural disaster blockade, unstable government, maoist, law and order situation and rumor that international media had been spreading regarding Nepal as an unsecured destination for tourist etc. if the current crisis is settled down and Hi-tech way of doing marketing is also consider for promoting tourism by these travel agencies the future of tourism industry will gloried to great extent than before. After going through the whole research what I have conclude is that most of the travel agencies knows the important of internet as marketing tools, due to the fact that most of them have a website and using email on regular basis but due to lack of knowledge, fund, and ignorance they are not utilizing internal marketing in professional way of seriously.

\section{Recommendation}

NTB and all the tourism related association should also take some initiatives and organize program regarding internet and its effectiveness as promotional tools and suggest way of doing it for travel agencies and other tourism related organization 
like hotels, trekking agencies etc. Here some of the recommendation how the tourism product can be promoted through internet.

- Education regarding internet and computer plays a vital role to determine every change in world. This study recommend that education about internet marketing is must for travel agents in order to promote its services through internet or can consult with internet marketing consultants like w.w.w.mountdigit.com for promoting its service through internet.

- Website must be display travel agencies profile, service it offer and information about place they can visit for that website should be made in interactive way be displayed.

- There are the few of the promotional way to promote site on internet in order to inform about the services on internet. If the correct method of promotion is used on internet to popularize travel agencies sites definitely it will contribute to promote tourism sector in Nepal to a great extent.

- The analysis clearly showed that the marketing activities which helps to draw the attention of tourist all over the world that includes the production of a range of booklets brochures, posters, audio-visuals, a website and other publicity material, agent and media familiarization trips and travel exhibitions and trade fairs. But Internet marketing plays an important role for the marketing of tourism in an effective and efficient way. Thus for the development and promotion of tourism industry in the desired and effective way. NTB should give priority to follow internet marketing.

\section{Bibliography}

Bhatia, A.K. (1997), Tourism Development: Principles and practices, New Delhi: Sterling Publishers Pvt. Ltd.

Bhattarai, T. (2006), Tourism Management, KTM, Ishwori Books \& Stationery.

Brunt, P. (1997), Market Research in travel and Tourism, Oxford: Butterworth-Heinermann.

Ghimire A. (2002), Travel \& tourism, Kathmandu: Ekata Books

Koirala, K.D. (2002), Market Research, Kathmandu: Buddha Academic Publishers and Distributors Pvt. Ltd.

Pant, P.R. (2010), Social Science Research and Thesis writing, Kathmandu, Buddha Academic Publisher \& Distributers Pvt. Ltd.

Pokharel, T.C. (2003), Marketing Strategies and plan for Tourism in Nepal-A Historical perspective "Image Nepal" KTM: Vol.13, No.9

Sthapit, A. (1996), Nepal travel trade journal, KTM, Vol. 3, No.1

Victor, T.C. (1998), Marketing in Travel \& tourism, Oxford: Heinemann professional publishing Ltd. 
Appendix

This questionnaire is prepared in order to collect the data for research article. Your kind participation in filling up this questionnaire will be highly appreciated.

Name of the travel Agency:

Location of the Travel Agency:

Date of Establishment:

No. of Employee:

1. Which promotional medium mostly suits your choice?

$\begin{array}{ll}\text { Website ( ) } & \text { E-marketing ( ) } \\ \text { Magazine ( ) } & \text { Personal contract }(\quad)\end{array}$

2. Do you have a website?

Yes ( ) No ( )

3. How long have you been using the internet?

Less than 1 year ( ) 1 to 5 years ( )

6 to 10 years ( ) More than 10 years $($ )

4. Do you have any idea about e-marketing?

Cost saving ( ) Time saving ( )

Effective ( ) Exposure of the world ( )

5. Which e-mail marketing method you are following?

Normal email ( ) New content notification ( )

Newsletters ( ) Bulk email marketing ( )

6. What is the reason behind not implementing internet as promotional tools?

Lack of fund ( ) Lack of knowledge ( )

Inefficient medium ( ) Others ( )

7. How do you evaluate the contribution made by internet?

Poor ( ) Satisfactory ( ) Good ( ) Very good ( )

8. Would you like to give any other inputs and suggestions to NTB for effective and efficient implementation of tourism marketing? 